\title{
Load flow analysis using Newton-Raphson method in presence of distributed generation
}

\author{
Tebbakh Noureddine, Labed Djamel \\ Laboratory of Electrical Engineering, Department of Electrical Engineering, University of Constantine 1, Constantine, \\ Algeria
}

\begin{tabular}{l} 
Article Info \\
\hline Article history: \\
Received Apr 18, 2020 \\
Revised Jan 19, 2021 \\
Accepted Feb 2, 2021 \\
\hline
\end{tabular}

Keywords:

Distributed generation Distribution networks Power flow system Power losses

Renewable sources

Voltage profile

\section{Corresponding Author:}

Tebbakh Noureddine

Laboratory of Electrical Engineering

Department of Electrical Engineering, University of Constantine 1, Constantine, Algeria

Email: tebbakh.noureddine@yahoo.com

\begin{abstract}
Distributed generations (DG), specially including renewable sources such as wind and sun are offering several opportunities for the currently in existence distribution networks and becoming one of the keys of treatment of its problems. Knowing the effects of each kind of DG on distribution networks is a primordial task because DG impacts differ from one kind to another. In this paper, we have analyzed and compared the effects of two kinds of DG, DG which provides real power only and DG which provides real power and reactive power at the same time connected at the critical bus in DN on the voltage profile, real and reactive power losses. We have proposed NewtonRaphson method using Matlab to investigate the impacts of these two kinds of DG on 57-bus IEEE distribution test system. The obtained results have been exposed in detail at the end of this paper.
\end{abstract}

This is an open access article under the CC BY-SA license.

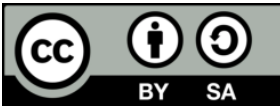

\section{INTRODUCTION}

These last years, the renewable sources integration in distribution networks (DN), desired by environmental protection demands and the market deregulation, raises the attention for decentralized generation problems [1]-[3]. Distributed generation (DG) is routinely called decentralized generation, on-site generation, embedded generation, or dispersed generation [4]-[6].

Thereafter the insertion of dispersed generation in distribution networks DN, the network voltage profile and power losses are affected [7]. The distributed generators contain several kinds of energy sources, as combustion gas turbines, induction generators, synchronous generators and renewable energy sources such as sun and wind, with modeste quantities. It supplied in the overtaking energy by means of the installation of the new distribution network. [8]-[10]. A DG unit should be exploited in a manner that may be exploited in parallel with the existing distribution networks [11].

The connection of distributed generation is reliant on: [12]

- $\quad$ the degree of generation previously linked

- the voltage level where in the DG will be linked

- the greatness of the DG be linked

- the category of the DG suggested

- the robustness of electrical network at the point of connection

So, DG sizes differed according to the category of users and applications, it can be linked at various voltage levels, small sizes are integrated at lowest evels, medium sizes and hight sizes are linked at medium 
and high voltage levels respectively [12]-[14]. The DG is grouped following the type power supplied to the distribution network, in several ranges [15]-[18]:

-Kind 1 : DG provides only real power: This kind contains microturbines, fuel cells, photovoltaic and batteries.

-Kind 2 : DG provides real power and reactive power: This kind cotains synchronous machine like Combined Heat and Power and gas turbine.

-Kind 3 : DG provides only reactive power: synchronous compensators are among this kind.

-Kind 4 : DG provides real power but soak up reactive power: This kind is made up of induction generators exploited in wind idustry.

Previous literature study shows that voltage value of DN should be preserved in a well-defined interval, this interval is between the nominal voltage of DN minus 5\% and the nominal voltage of DN plus $5 \%$. It means that the voltage value at all the busses is in this range [19], [20], power losses in transmission and distribution lines achieve $4 \%$ to $5 \%$ of total usage [21]. Thus, the minimization of active and reactive power losses in the distribution networks have a great importance for utilities in worldwide [22], [23]. The incorporation of dispersed generation unit at unreliable location and size may have adverse effects of increased system losses and costs. [24], [25], on other hand optimal placement enhance the DN behavior on voltage profile plan, decrease power losses, and increase quality of supplied power [26], [27].

Furthermore, several researchers have carried out works on the right site, size and number of DG units in DN. These works vary between the analytical and optimization approaches which have perfectly determined the ideal site, size and number of DG units. Autor in [28] suggested a method founded on cuckoo search algorithm (CSA) to detect the right site and dimension of DG and STATCOM in the radial distribution netwoks RDS, the suggested method is tested on several IEEE test systems such as 33 bus and 136 bus, the obtained results were faced up to other approaches already exist, these results indicate that the suggested approach has a precise viewpoint of this crtical issue and causes positive effects on the DN behavior. Autor in [29] presented a load flow algorithm based on the backward/forward sweep approach to determine load flow issues in RDS, the suggested approach can be used in various DN applications. P. Guru et al in [30] used PSO algorithm to investigate the ideal arrangement of DG in IEEE standard 33 bus, the obtained outcomes have also been verified by comparing with the previous work discussed in literature survey. M. Daneshvaret et al in [31] used exchange market algorithm (EMA) to detect the right DG location and size in RDS, EMA applied to solve the DG alloction and size problem on various test systems effectively that includes 33 bus and 69 bus IEEE test systems, the numerical results indicated that active and reactive power losses are minimized, the voltage profile is improved, and the cost of energy not supplied is minimized. K. Adetunji et al in [32] improved the particle swarm optimization (PSO) and the whale optimization algorithm (WOA) to have the precise siting and sizing of DG units. Autors in [33] proposed gravitational search algorithm (GSA) to find the optimal site of DG and D-STATCOM the algorithm has applied on 69 bus IEEE test system and other systems. Another approach adopted by D. Kim and I. Kim [34] wherein they proposed a Newton-Raphson algorithm using MATLAB for the optimization of DG units. In this paper, we have chosen Newton-Raphson method using Matlab to investigate the impacts of two kinds of DG connected at the critical bus on DN behavior. It is analyzed the impact of DGs on voltage profile and power losses.

\section{RESEARCH METHOD}

\subsection{Load flow analysis}

Power flow study is the significant basic tool to analyse power systems and study their operations [35], the aim of load flow analysis (LFA) is to compute the voltage, phase plus real and reactive power of the whole busses in the power systems. The buses types in the LFA are swing bus where we know voltage and phase, PV bus where we know voltage and real power, PQ bus where we know real and reactive power [36]. Newton-Raphson and Fast-Decoupled methods are most known in power flow studies. The nodal power system equation is used to drive the basic power flow PF [37]. As shown in (1) is for n-bus system.

$$
\left[I_{i}\right]=\left[Y_{i j}\right] *\left[V_{j}\right]
$$

where

$\left[Y_{i j}\right]$ is admittance Matrix,

$\left[I_{i}\right]$ is currents value at each node Matrix.

$\left[V_{j}\right]$ is buses voltages Matrix.

$$
S_{i}=V_{i} * I_{i}^{*}=P_{i}+J Q_{i}
$$


As results, we have;

$$
\begin{aligned}
& P_{i-j} Q_{i}=V_{i}^{*} * I_{i}=V_{i}^{*} * \sum_{j=1}^{n}\left(Y_{i j} * V_{j}\right) \\
& P_{i}=\left|V_{i}\right| \sum_{j=1}^{n b}\left|V_{j}\right|\left[G_{i j} \cos \left(\delta_{i}-\delta_{j}\right)+B_{i j} \sin \left(\delta_{i}-\delta_{j}\right)\right] \\
& Q_{i}=\left|V_{i}\right| \sum_{j=1}^{n b}\left|V_{j}\right|\left[G_{i j} \sin \left(\delta_{i}-\delta_{j}\right)-B_{i j} \cos \left(\delta_{i}-\delta_{j}\right)\right] \\
& i=1,2 \ldots \ldots \ldots, n b
\end{aligned}
$$

where

$\left|V_{i}\right| \quad$ : is voltage magnitude per-unit at bus (i).

$\left|I_{i}{ }^{*}\right| \quad:$ is conjugate current magnitude per-unit at bus (i).

$\left|P_{i}\right| \quad:$ is real power injected per-unit injected at the bus (i).

$\left|Q_{i}\right| \quad:$ is reactive power per-unit injected at the bus (i)

$G_{i j}$ and $B_{i j} \quad$ : are conductance and susceptance shunted to the line (ij).

$\delta_{i} \quad:$ is voltage angle of the bus (i)

$\delta_{j} \quad:$ is voltage angle of the bus $(\mathrm{j})$

$\mathrm{Nb} \quad$ : number of buses.

Power losses in DN vary according to several factors, as the system configuration, the losses level across system power lines, transformers, etc. there are two categories of power losses: real power losses and reactive power losses. Total power losses in DN are calculated by the (6) and (7) [38].

$$
\begin{aligned}
& P_{\text {Loss }}=\sum_{i=1}^{n b r}\left|I_{i}^{2}\right| * r_{i} \\
& Q_{\text {Loss }}=\sum_{i=1}^{n b r}\left|I_{i}^{2}\right| * x_{i}
\end{aligned}
$$

where

nbr : branches number in system

|Ii $\quad:$ the current magnitude circulated in branch (i)

xi and ri : reactance and resistance of branch (i).

Four variables are required to comput power flow parametres, which are $\mathrm{P}, \mathrm{Q}, \mathrm{V}$ and $\delta=\delta_{i}-\delta_{j}$.

\subsection{Newton-Raphson method}

It is observable that in the nonlinear (4) and (5), the number of functions and the number of variables are unequals, Thus the classical methods cannot solve these equations; which explains the use of numerical methods to solve this kind of equations Newton-Raphson method, based on the Jacobian matrix. The elements of jacobian matrix are partials derivatives values of $\mathrm{P}$ or $\mathrm{Q}$ with respect to $\mathrm{V}$ or $\delta$, then we write the (8) [39].

$$
\left[\begin{array}{c}
\Delta P_{2} \\
\Delta P_{3} \\
\vdots \\
\Delta P_{n} \\
\Delta Q_{m+1} \\
\Delta Q_{m+2} \\
\vdots \\
\Delta Q_{n}
\end{array}\right]=\left[\begin{array}{cccccccc}
\frac{\partial P_{2}}{\partial \delta_{2}} & \frac{\partial P_{2}}{\partial \delta_{3}} & \cdots & \frac{\partial P_{2}}{\partial \delta_{n}} & \frac{\partial P_{2}}{\partial\left|\bar{V}_{m+1}\right|} & \frac{\partial P_{2}}{\partial\left|\bar{V}_{m+2}\right|} & \cdots & \frac{\partial P_{2}}{\partial\left|\bar{V}_{n}\right|} \\
\frac{\partial P_{3}}{\partial \delta_{2}} & \frac{\partial P_{3}}{\partial \delta_{3}} & \cdots & \frac{\partial P_{3}}{\partial \delta_{n}} & \frac{\partial P_{3}}{\partial\left|\bar{V}_{m+1}\right|} & \frac{\partial P_{3}}{\partial\left|\bar{V}_{m+2}\right|} & \cdots & \frac{\partial P_{3}}{\partial\left|\bar{V}_{n}\right|} \\
\vdots & \vdots & \vdots & \vdots & \vdots & \vdots & \vdots & \vdots \\
\frac{\partial P_{n}}{\partial \delta_{2}} & \frac{\partial P_{n}}{\partial \delta_{3}} & \cdots & \frac{\partial P_{n}}{\partial \delta_{n}} & \frac{\partial P_{n}}{\partial\left|\bar{V}_{m+1}\right|} & \frac{\partial P_{n}}{\partial\left|\bar{V}_{m+2}\right|} & \cdots & \frac{\partial P_{n}}{\partial\left|\bar{V}_{n}\right|} \\
\frac{\partial Q_{m+1}}{\partial \delta_{2}} & \frac{\partial Q_{m+1}}{\partial \delta_{3}} & \cdots & \frac{\partial Q_{m+1}}{\partial \delta_{n}} & \frac{\partial Q_{m+1}}{\partial\left|\bar{V}_{m+1}\right|} & \frac{\partial Q_{m+1}}{\partial\left|\bar{V}_{m+2}\right|} & \cdots & \frac{\partial Q_{m+1}}{\partial\left|\bar{V}_{n}\right|} \\
\frac{\partial Q_{m+2}}{\partial \delta_{2}} & \frac{\partial Q_{m+2}}{\partial \delta_{3}} & \cdots & \frac{\partial Q_{m+2}}{\partial \delta_{n}} & \frac{\partial Q_{m+2}}{\partial\left|\bar{V}_{m+1}\right|} & \frac{\partial Q_{m+2}}{\partial\left|\bar{V}_{m+2}\right|} & \cdots & \frac{\partial Q_{m+2}}{\partial\left|\bar{V}_{n}\right|} \\
\vdots & \vdots & \vdots & \vdots & \vdots & \vdots & \vdots & \vdots \\
\frac{\partial Q_{n}}{\partial \delta_{2}} & \frac{\partial Q_{n}}{\partial \delta_{3}} & \cdots & \frac{\partial Q_{n}}{\partial \delta_{n}} & \frac{\partial Q_{n}}{\partial\left|\bar{V}_{m+1}\right|} & \frac{\partial Q_{n}}{\partial\left|\bar{V}_{m+2}\right|} & \cdots & \frac{\partial Q_{n}}{\partial\left|\bar{V}_{n}\right|}
\end{array}\right]\left[\begin{array}{c}
\Delta \\
\Delta \delta_{2} \\
\Delta \delta_{3} \\
\vdots \\
\Delta \delta_{n} \\
\Delta\left|\bar{V}_{m+1}\right| \\
\Delta\left|\bar{V}_{m+2}\right| \\
\vdots \\
\Delta\left|\bar{V}_{n}\right|
\end{array}\right]
$$

where:

$\Delta P_{i}$ and $\Delta Q_{i}:$ are power gap at bus (i).

$\Delta \delta_{i} \quad$ : Voltage angle gap at bus (i). 
Voltage magnitude and phase angle variations were getting by:

$$
\left[\begin{array}{c}
{\left[\Delta \delta^{(k)}\right]} \\
{\left[\Delta \mid \overline{\left.V\right|^{(k)}}\right]}
\end{array}\right]=[J]^{-1}\left[\begin{array}{l}
{\left[\Delta P^{(k)}\right]} \\
{\left[\Delta Q^{(k)}\right]}
\end{array}\right]
$$

Thereby the new voltage magnitude and voltage angle values are:

$$
\left\{\begin{array}{l}
V_{i}^{k+1}=V_{i}^{k}+\Delta V_{i}^{k} \\
\delta_{i}^{k+1}=\delta_{i}^{k}+\Delta \delta_{i}^{k}
\end{array}\right.
$$

The iterative system stops when the convergence criterion is completed.

$$
\left\{\begin{array}{l}
\left|\Delta P_{i}^{(k)}\right|<\varepsilon \\
\left|\Delta Q_{i}^{(k)}\right|<\varepsilon
\end{array}\right.
$$

where:

$\mathrm{k}$ is iteration

$\varepsilon \quad$ is tolerance

\subsection{Methodology}

An IEEE 57-bus distribution system contains seven generators; forty-two load buses (PQ buses) and eighty branches have been considered. The system to study has been operated in Matlab using NewtonRaphson method;the IEEE 57-bus distribution system is presented in Figure 1. Lines data and generators power limits are provided in Tables 2 and 3 in the appendix [40].

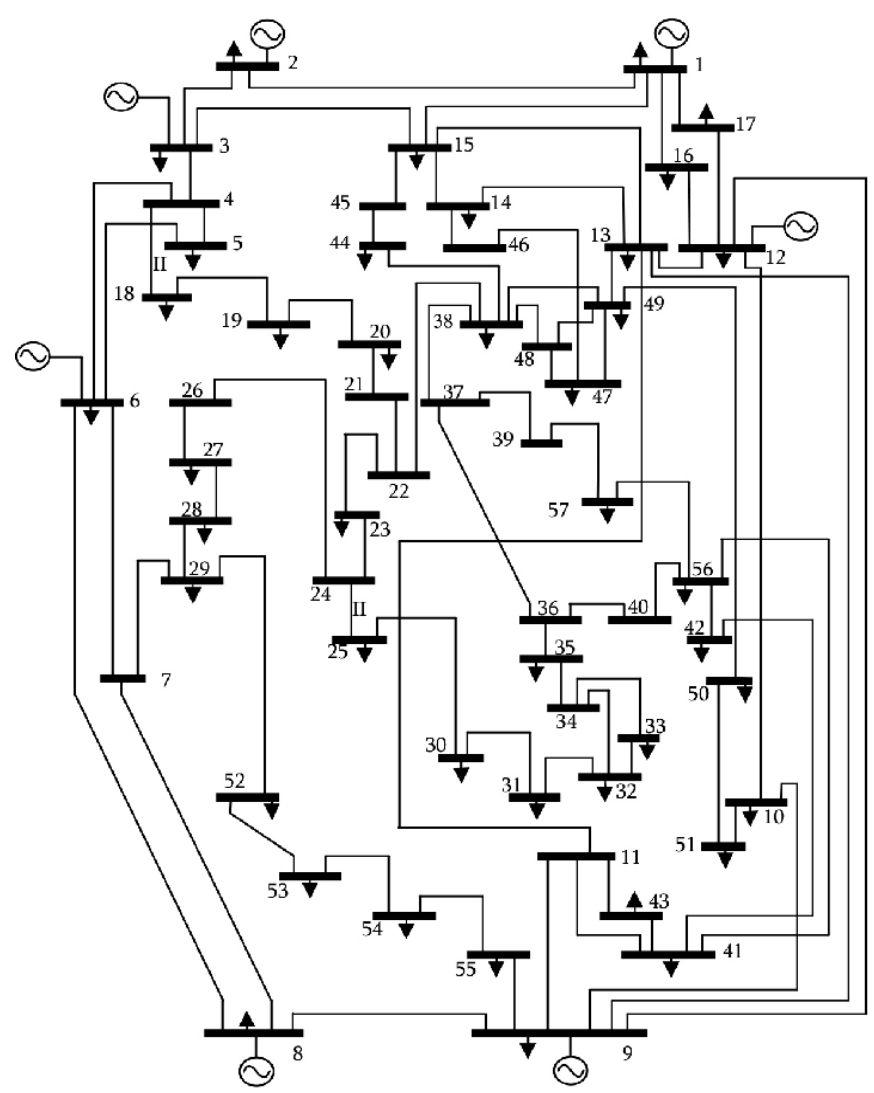

Figure 1. Single line diagram IEEE 57 bus test system 
The methodology includes three stages. The stage number one is to interpret the load flow analysis on the power system without DG. The stage number two is to located buses with voltage violation. Avoltage violation appears when the bus voltage is less than $95 \%$ or more than $105 \%$ of per-unit nominal voltage and the stage number three is to interpret the load flow analysis with the DG attached at the critical bus. DG which provides real power only (kind1) and a DG provides real power and reactive power at the same time (Kind2) have been connected separately at the bus with the significant voltage violation (critical bus).

There are proposed the following scenarios:

- Case 00: simulation without connecting any DG in the distribution network.

- Case 01: Connecting DG with $\mathrm{P}_{\mathrm{DG}}=12.5 \mathrm{MW}, \mathrm{Q}_{\mathrm{DG}}=0 \mathrm{MVAr}$ and Power factor $=1$

- Case 02: Connecting DG with $\mathrm{P}_{\mathrm{DG}}=25 \mathrm{MW}, \mathrm{Q}_{\mathrm{DG}}=0 \mathrm{MVAr}$ and Power factor $=1$

- Case 03: Connecting DG with $\mathrm{P}_{\mathrm{DG}}=12.5 \mathrm{MW}, \mathrm{Q}_{\mathrm{DG}}=6 \mathrm{MVAr}$ and Power factor $=0.90$

- Case 04: Connecting DG with $\mathrm{P}_{\mathrm{DG}}=25 \mathrm{MW}, \mathrm{Q}_{\mathrm{DG}}=12 \mathrm{MVAr}$ and Power factor $=0.90$

\section{RESULTS AND DISCUSSION}

The objectif of this section is to examine the effect of DG connected at the critical bus in distribution network. As it was mentioned at methodology sub-section. The load flow analysis was carry out on the distribution network without distributed generation, this will be used as a reference case.

- $\quad$ Case $n^{\circ}$ 00: The system was operated without linking any DG, the reference case results indicate that voltage of busses 31, 33, 46 and 51 listed in Table 1 is not within the 5 percent margin, the rest of busses are within the allowed voltage range, the bus number 31 is the bus with significant voltage violation, the Figures 2, 3 and 4 illustrate the voltage profile. Real power and reactive power losses are equals to 27.86 MW and 121.67 MVAr successively.

Table 1 . Buses with voltage violation in case 00

\begin{tabular}{cccc}
\hline Bus & Per unit voltage & Reference voltage & $\Delta \mathrm{V} \mid \%$ \\
\hline 31 & 0.936 & 1.00 & 6.40 \\
33 & 0.948 & 1.00 & 5.20 \\
46 & 1.060 & 1.00 & 6.00 \\
51 & 1.052 & 1.00 & 5.20 \\
\hline
\end{tabular}

To evaluate the impact of DG connected at the critical bus on the system power losses and voltage profile, the following cases where considered.

- Case $\mathrm{n}^{\circ}$ 01: a 12.50 MW DG was linked to bus 31, the results indicate that power losses decrease and become 25.74 MW and 112.93 MVAr.

- Case $\mathrm{n}^{\circ}$ 02: a $25 \mathrm{MW}$ DG was connected to bus 31, the results indicate that power losses have continue to decrease and become 24.94 MW and 108.20 MVAr.

- Case $\mathrm{n}^{\circ}$ 03: a 12.50 MW and 6 MVAr DG was connected to bus 31, the results indicate that power losses increase little bit and become 25.47 MW and 112.03 MVAr.

- Case ${ }^{\circ}$ 04: a $25 \mathrm{MW}$ and $12 \mathrm{MVAr}$ DG was connected to bus 31, in this case we have got the best results 24.52 MW and 106.91 MVAr.

\subsection{Voltage profile}

\subsubsection{DG kind 01}

The Figure 2 indicate that in the case $n^{\circ} 01(12.5 \mathrm{MW})$ the voltage magnitude is improved than in the case $\mathrm{n}^{\circ} 02(25 \mathrm{MW})$, increasing DG size is not necessarily a good fact.

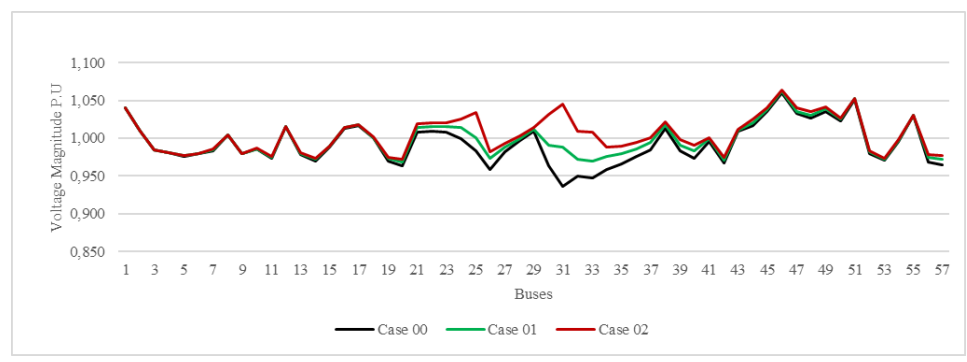

Figure 2. Voltage profile variations with DG kind 01 


\subsubsection{DG kind 02}

The Figure 3 revealed that the voltage magnitude in the case $n^{\circ} 03(12.5 \mathrm{MW}$ and $6 \mathrm{MVAr})$ is adequate, but in the case $\mathrm{n}^{\circ} 04$ the voltage magnitude at bus 31 is increased over the international standards range (1.128 p u), increasing DG size is not necessarily a good fact in this kind of DG. The Figure 4 also show that case $\mathrm{n}^{\circ} 03$ is perfect than case $\mathrm{n}^{\circ} 01$. So DG which provides both active and reactive power is more useful than DG which provides active power only.

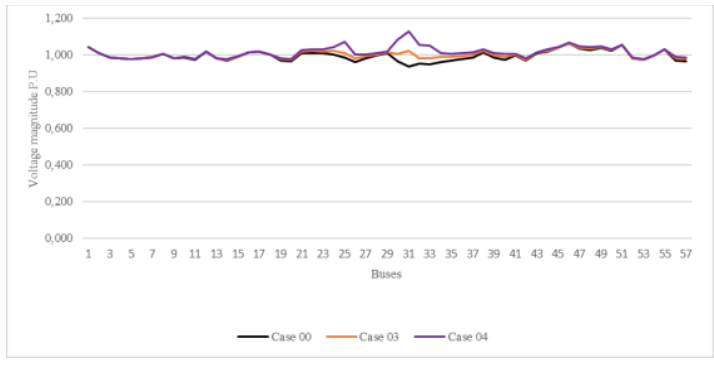

Figure 3. Voltage profile variations with DG kind 02

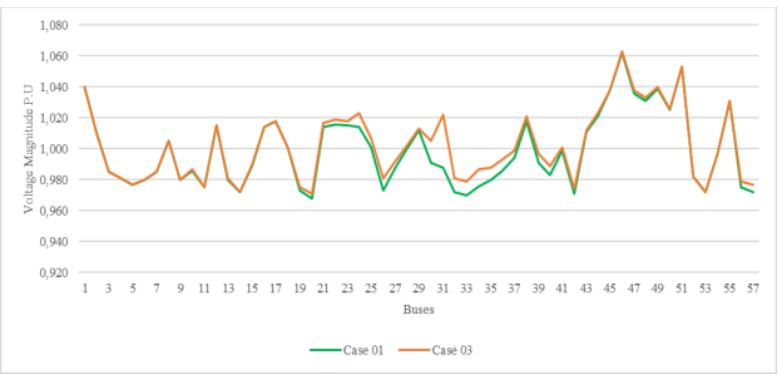

Figure 4. Comparison among case $n^{\circ} 01$ et case 03

\subsection{Power losses}

Real and reactive power losses without any interconnecting DG are equals to 27.86 MW and 121.67 MVAr. It is clear from the Figures 5 (a) and (b) that kind 01 case 01 real power losses were diminished by 7,61\% and reactive power losses were diminished by $7,18 \%$, case 02 real power losses were diminished by $10,48 \%$ and reactive power losses were diminished by $11,07 \%$, kind 02 case 03 real power losses were diminished by $8,57 \%$ and reactive power losses were diminished by 7,70 \% case 04 real power losses were diminished by $11,99 \%$ and reactive power losses were diminished by $12,13 \%$ as DG size is increased as power losses are reduced, especially for DG type 02 . Therefore, size and kind of a DG play an accurate role in power losses.

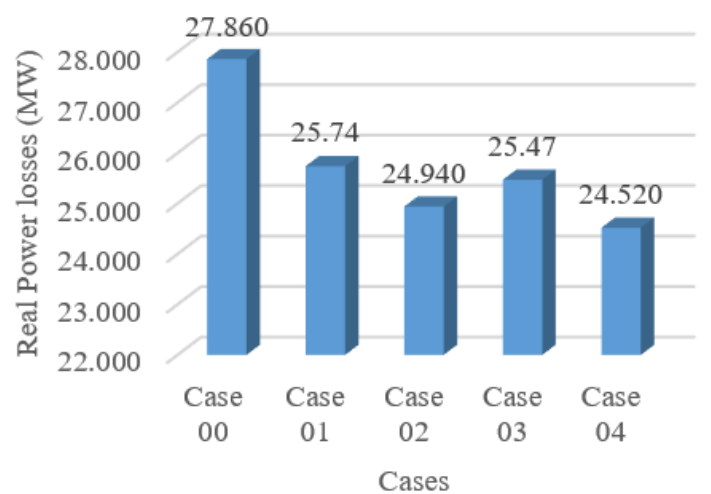

(a)

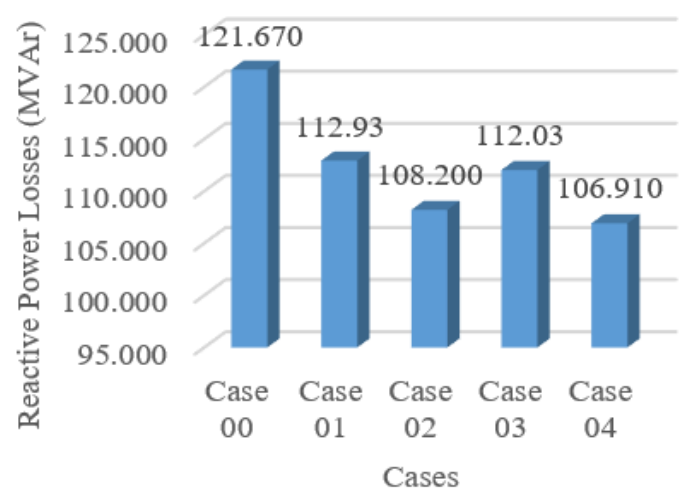

(b)

Figure 5. Power losses variations; (a) real power, (b) reactive power

\section{CONCLUSION}

Due the current and future trend of electricity users (suppliers and consumers) is set towards increasing the integration of DGs, in particular renewable energy sources, a complete analysis has to be done before linking DG units to predict the impacts of DGs kind and size on distribution network behavior, but without forgetting the costs. In this paper, the authors used a simple numerical method to compare the impact of a DG provides real power and reactive power at the same time and DG provides only real power on distribution network voltage profile, real power losses and reactive power losses at the critical bus. NewtonRaphson load flow method without and with distributed generation has been used. From the results, it has 
been shown that integration of the two kinds in distribution networks (critical bus) has allowed enhancing the system in terms of power; unfortunately, when we incease the size of DGs a negative effect apreared on voltage profile at the critical bus and the neighbor's buses. Results obtained are confirmed by A.S.O. Ogunjuyigbe, et al., [41] and other results available in the literature. Therefore, DG provides active power and reactive power at the same time is more useful than DG provides only active power and increasing DG size is not necessarily a good fact for distribution networks.

\section{APPENDIX}

Table 2. Lines data

\begin{tabular}{|c|c|c|c|c|c|c|}
\hline $\mathrm{N}^{\circ}$ & F - Bus & $\mathrm{T}-\mathrm{Bus}$ & $\mathrm{r}$ & $\mathrm{x}$ & $\mathrm{b}$ & Ratio \\
\hline 1 & 1 & 2 & 0.0083 & 0.0280 & 0.1290 & 0 \\
\hline 2 & 2 & 3 & 0.0298 & 0.0850 & 0.0818 & 0 \\
\hline 3 & 3 & 4 & 0.0112 & 0.0366 & 0.0380 & 0 \\
\hline 4 & 4 & 5 & 0.0625 & 0.1320 & 0.0258 & 0 \\
\hline 5 & 4 & 6 & 0.0430 & 0.1480 & 0.0348 & 0 \\
\hline 6 & 6 & 7 & 0.0200 & 0.1020 & 0.0276 & 0 \\
\hline 7 & 6 & 8 & 0.0339 & 0.1730 & 0.0470 & 0 \\
\hline 8 & 8 & 9 & 0.0099 & 0.0505 & 0.0548 & 0 \\
\hline 9 & 9 & 10 & 0.0369 & 0.1679 & 0.0440 & 0 \\
\hline 10 & 9 & 11 & 0.0258 & 0.0848 & 0.0218 & 0 \\
\hline 11 & 9 & 12 & 0.0648 & 0.2950 & 0.0772 & 0 \\
\hline 12 & 9 & 13 & 0.0481 & 0.1580 & 0.0406 & 0 \\
\hline 13 & 13 & 14 & 0.0132 & 0.0434 & 0.0110 & 0 \\
\hline 14 & 13 & 15 & 0.0269 & 0.0869 & 0.0230 & 0 \\
\hline 15 & 1 & 15 & 0.0178 & 0.0910 & 0.0988 & 0 \\
\hline 16 & 1 & 16 & 0.0454 & 0.2060 & 0.0546 & 0 \\
\hline 17 & 1 & 17 & 0.0238 & 0.1080 & 0.0286 & 0 \\
\hline 18 & 3 & 15 & 0.0162 & 0.0530 & 0.0544 & 0 \\
\hline 19 & 4 & 18 & 0.0000 & 0.5550 & 0.0000 & 0.970 \\
\hline 20 & 4 & 18 & 0.0000 & 0.4300 & 0.0000 & 0.978 \\
\hline 21 & 5 & 6 & 0.0302 & 0.0641 & 0.0124 & 0 \\
\hline 22 & 7 & 8 & 0.0139 & 0.0712 & 0.0194 & 0 \\
\hline 23 & 10 & 12 & 0.0277 & 0.1262 & 0.0328 & 0 \\
\hline 24 & 11 & 13 & 0.0223 & 0.0732 & 0.0188 & 0 \\
\hline 25 & 12 & 13 & 0.0178 & 0.0580 & 0.0604 & 0 \\
\hline 26 & 12 & 16 & 0.0180 & 0.0813 & 0.0216 & 0 \\
\hline 27 & 12 & 17 & 0.0397 & 0.1790 & 0.0476 & 0 \\
\hline 28 & 14 & 15 & 0.0171 & 0.0547 & 0.0148 & 0 \\
\hline 29 & 18 & 19 & 0.4610 & 0.6850 & 0.0000 & 0 \\
\hline 30 & 19 & 20 & 0.2830 & 0.4340 & 0.0000 & 0 \\
\hline 31 & 21 & 20 & 0.0000 & 0.7767 & 0.0000 & 1.043 \\
\hline 32 & 21 & 22 & 0.0736 & 0.1170 & 0.0000 & 0 \\
\hline 33 & 22 & 23 & 0.0099 & 0.0152 & 0.0000 & 0 \\
\hline 34 & 23 & 24 & 0.1660 & 0.2560 & 0.0084 & 0 \\
\hline 35 & 24 & 25 & 0.0000 & 1.1820 & 0.0000 & 1 \\
\hline 36 & 24 & 25 & 0.0000 & 1.2300 & 0.0000 & 1 \\
\hline 37 & 24 & 26 & 0.0000 & 0.0473 & 0.0000 & 1.043 \\
\hline 38 & 26 & 27 & 0.1650 & 0.2540 & 0.0000 & 0 \\
\hline 39 & 27 & 28 & 0.0618 & 0.0954 & 0.0000 & 0 \\
\hline 40 & 28 & 29 & 0.0418 & 0.0587 & 0.0000 & 0 \\
\hline 41 & 7 & 29 & 0.0000 & 0.0648 & 0.0000 & 0.967 \\
\hline 42 & 25 & 30 & 0.1350 & 0.2020 & 0.0000 & 0 \\
\hline 43 & 30 & 31 & 0.3260 & 0.4970 & 0.0000 & 0 \\
\hline 44 & 31 & 32 & 0.5070 & 07550 & 0.0000 & 0 \\
\hline 45 & 32 & 33 & 0.0392 & 0.0360 & 0.0000 & 0 \\
\hline 46 & 34 & 32 & 0.0000 & 0.9530 & 0.0000 & 0.975 \\
\hline 47 & 34 & 35 & 0.0520 & 0.0780 & 0.0032 & 0 \\
\hline 48 & 35 & 36 & 0.0430 & 0.0537 & 0.0016 & 0 \\
\hline 49 & 36 & 37 & 0.0290 & 0.0366 & 0.0000 & 0 \\
\hline 50 & 37 & 38 & 0.0651 & 0.1009 & 0.0020 & 0 \\
\hline 51 & 37 & 39 & 0.0239 & 0.0379 & 0.0000 & 0 \\
\hline 52 & 36 & 40 & 0.0300 & 0.0466 & 0.0000 & 0 \\
\hline 53 & 22 & 38 & 0.0192 & 0.0295 & 0.0000 & 0 \\
\hline 54 & 11 & 41 & 0.0000 & 0.7490 & 0.0000 & 0.955 \\
\hline 55 & 41 & 42 & 0.2070 & 0.3520 & 0.0000 & 0 \\
\hline 56 & 41 & 43 & 0.0000 & 0.4120 & 0.0000 & 0 \\
\hline 57 & 38 & 44 & 0.0289 & 0.0585 & 0.0020 & 0 \\
\hline 58 & 15 & 45 & 0.0000 & 0.1042 & 0.0000 & 0.955 \\
\hline 59 & 14 & 46 & 0.0000 & 0.0735 & 0.0000 & 0.900 \\
\hline 60 & 46 & 47 & 0.0230 & 0.0680 & 0.0032 & 0 \\
\hline 61 & 47 & 48 & 0.0182 & 0.0233 & 0.0000 & 0 \\
\hline
\end{tabular}




\begin{tabular}{llllllc}
\hline 62 & 48 & 49 & 0.0834 & 0.1290 & 0.0048 & 0 \\
63 & 49 & 50 & 0.0801 & 0.1280 & 0.0000 & 0 \\
64 & 50 & 51 & 0.1386 & 0.2200 & 0.0000 & 0 \\
65 & 10 & 51 & 0.0000 & 0.0712 & 0.0000 & 0.930 \\
66 & 13 & 49 & 0.0000 & 0.1910 & 0.0000 & 0.895 \\
67 & 29 & 52 & 0.1442 & 0.1870 & 0.0000 & 0 \\
68 & 52 & 53 & 0.0762 & 0.0984 & 0.0000 & 0 \\
69 & 53 & 54 & 0.1878 & 0.2320 & 0.0000 & 0 \\
70 & 54 & 55 & 0.1732 & 0.2265 & 0.0000 & 0 \\
71 & 11 & 43 & 0.0000 & 0.1530 & 0.0000 & 0.958 \\
72 & 44 & 45 & 0.0624 & 0.1242 & 0.0040 & 0 \\
73 & 40 & 56 & 0.0000 & 1.1950 & 0.0000 & 0.958 \\
74 & 56 & 41 & 0.5530 & 0.5490 & 0.0000 & 0 \\
75 & 56 & 42 & 0.2125 & 0.3540 & 0.0000 & 0 \\
76 & 39 & 57 & 0.0000 & 1.3550 & 0.0000 & 0.980 \\
77 & 57 & 56 & 0.1740 & 0.2600 & 0.0000 & 0 \\
78 & 38 & 49 & 0.1150 & 0.1770 & 0.0030 & 0 \\
79 & 38 & 48 & 0.0312 & 0.0482 & 0.0000 & 0 \\
80 & 9 & 55 & 0.0000 & 0.1205 & 0.0000 & 0.940 \\
\hline
\end{tabular}

Table 3. Generators power limits

\begin{tabular}{cccccc}
\hline $\mathrm{N}^{\circ}$ & Bus & $\mathrm{P} \max (\mathrm{MW})$ & $\mathrm{P} \min (\mathrm{MW})$ & $\mathrm{Q} \max (\mathrm{MVAr})$ & $\mathrm{Q} \min (\mathrm{MVAr})$ \\
\hline 1 & 1 & 575.88 & 0 & 200 & -140 \\
2 & 2 & 100 & 0 & 50 & -17 \\
3 & 3 & 140 & 0 & 60 & -10 \\
4 & 6 & 100 & 0 & 25 & -8 \\
5 & 8 & 550 & 0 & 200 & -140 \\
6 & 9 & 100 & 0 & 9 & -3 \\
7 & 12 & 410 & 0 & 155 & -150 \\
\hline
\end{tabular}

\section{REFERENCES}

[1] A. Sorin, et al., "Solutions for energy losses reduction in power networks with renewable energy sources," 2016 International Conference on Applied and Theoretical Electricity (ICATE), Craiova, 2016, pp. 1-6.

[2] L.Ionel, et al., "Impact of Distributed Generation on voltage profile and power losses in a test power grid," 2017 International Conference on Optimization of Electrical and Electronic Equipment (OPTIM) \& 2017 Intl Aegean Conference on Electrical Machines and Power Electronics (ACEMP), Brasov, 2017, pp. 128-133.

[3] G. Mujtaba, et al., "Implementation of Distributed Generation with Solar Plants in a $132 \mathrm{kV}$ Grid Station at Layyah Using ETAP," International Journal of Photoenergy, vol. 2020, pp. 1-14, 2020.

[4] Y. Mulyadi, T. Sucita, and M. D. Rahmawan, "Analysis Impact of Distributed Generation Injection to Profile of Voltage and Short-Circuit Fault in 20 kV Distribution Network System," IOP Conference Series: Materials Science and Engineering, vol. 288, no. 1, pp. 1-15, 2018.

[5] V. S. Bhadoria, N. S. Pal, and V. Shrivastava, "A review on distributed generation definitions and DG impacts on distribution system," Conference: International Conference on Advanced Computing and Communication Technologies (ICACCT TM-2013), vol. 7, 2013.

[6] D. Labed, "Production Decentralisee Et Couplage Au Réseau," Ph. D Thesis. Department of electrical engineering, university frères Mentouri -Constantine1, Algeria. 2008.

[7] N. Cristian, and B. D. Al Ameri Ahmed, "Impact Analysis of Distributed Generation on Mesh and Radial distribution network," University of Kufa, 2013.

[8] P. P. Barker, and R. W. DeMello, "Determining the impact of distributed generation on power systems. I. Radial distribution systems,"2000 Power Engineering Society Summer Meeting (Cat. No.00CH37134), Seattle, WA, 2000, pp. 1645-1656, vol. 3 .

[9] S. Jhansi, "Effects of Distributed Generation on Electrical Power Network and Protection," Journal of Electrical and Electronic Systems, vol. 8, no. 1, pp. 1-3, 2019

[10] L. T. C. Borges, and D. M. Falcão, "Impact of distributed generation allocation and sizing on reliability, losses and voltage profile," 2003 IEEE Bologna Power Tech Conference Proceedings, Bologna, Italy, 2003, pp. 5, vol. 2.

[11] T. S. Basso, and R. DeBlasio, "IEEE 1547 series of standards: interconnection issues," IEEE Transactions on Power Electronics, vol. 19, no. 5, pp. 1159-1162, 2004.

[12] N. K. Roy and H. R Pota, "Current status and issues of concern for the integration of distributed generation into electricity networks," IEEE Systems Journal, vol. 9, no. 3, pp. 933-944, 2014.

[13] N. Jenkins, J. B. Ekanayak and G. Strbac, "Distributed generation,"London, U. K: IET, 2010.

[14] K. Doğanşahin, et al., "Maximum permissible integration capacity of renewable DG units based on system loads," Energies, vol. 11, no. 1, p. 255, 2018. 
[15] A. Bouafia and D. Labed, "Contribution of DGs in the stability and voltage drop reduction for future MV network in desert regions,"International Journal of Power Electronics and Drive System (IJPEDS), vol. 11, no. 2, pp. 977-987, 2020.

[16] R. Seyed-Ehsan, et al., "Impact of distributed generation on protection and voltage regulation of distribution systems: A review," Renewable and Sustainable Energy Reviews, vol. 105, pp. 157-167, 2019.

[17] H. Q. Duong, and N. Mithulananthan, "Multiple distributed generator placement in primary distribution networks for loss reduction," IEEE Transactions on Industrial Electronics, vol. 60, no. 4, pp. 1700-1708, 2013.

[18] A. M. Eltamaly, et al., "Reliability/Security of Distribution System Network under Supporting by Distributed Generation," Insight-Energy Science, vol. 2, no. 1, pp. 1-14, 2019.

[19] J. C. Edward, et al., "Integration issues of distributed generation in distribution grids," Proceedings of the IEEE, vol. 99, no. 1, pp. 28-39, 2011.

[20] A. Raj, et al., "Investigation of distributed generation units placement and sizing based on voltage stability condition indicator (VSCI)," International Journal of Power Electronics and Drive Systems (IJPESD), vol. 10, no. 3, pp. 1317-1323, 2019.

[21] I. Labed and D. Labed, "Power flow variation based on extreme learning machine algorithm in power system," International Journal of Power Electronics and Drive Systems (IJPEDS), vol. 10, no. 3, pp. 1244-1254, 2019.

[22] H. Q. Duong, N. Mithulananthan, and R. C. Bansal, "Analytical expressions for DG allocation in primary distribution networks," IEEE Transactions on energy conversion, vol. 25, no. 3, pp. 814-820, 2010.

[23] A. S. Hassan, etal., "Optimization techniques applied for optimal planning and integration of renewable energy sources based on distributed generation: Recent trends," Cogent Engineering, vol. 7, no. 1, 2020.

[24] M. Quraan., et al., "Impact of integrating photovoltaic based DG on distribution network harmonics," 2017 IEEE International Conference on Environment and Electrical Engineering and 2017 IEEE Industrial and Commercial Power Systems Europe (EEEIC / I\&CPS Europe), Milan, 2017, pp. 1-5.

[25] N. John, V. Janamala, and J. Rodrigues, "Impact of Variable Distributed Generation on Distribution System Voltage Stability," 2019 International Conference on Data Science and Communication (IconDSC), Bangalore, India, 2019, pp. 1-5.

[26] P. S. Georgilakisand N. D. Hatziargyriou, "Optimal Distributed Generation Placement in Power Distribution Networks: Models, Methods, and Future Research," IEEE Transactions on Power Systems, vol. 28, no. 3, pp. 3420-3428, 2013.

[27] N. Ismail, et al., "Effect of voltage deviations on power distribution losses in presence of DG technology," 2015 International Conference on Renewable Energy Research and Applications (ICRERA), Palermo, 2015, pp. 766-771.

[28] T. Yuvaraj and K. Ravi, "Multi-objective simultaneous DG and DSTATCOM allocation in radial distribution networks using cuckoo searching algorithm,"Alexandria engineering journal, vol. 57, no. 4, pp. 2729-2742, 2018.

[29] S. Ouali and A. Cherkaoui, "An Improved Backward/Forward Sweep Power Flow Method Based on a New Network Information Organization for Radial Distribution Systems," Journal of Electrical and Computer Engineering,vol. 2020, 2020.

[30] P. Guru., et al., "Optimal Allocation of Distributed Generation for Power Loss Minimization using PSO Algorithm," 2019 3rd International Conference on Recent Developments in Control, Automation \& Power Engineering (RDCAPE), NOIDA, India, 2019, pp. 22-26.

[31] M. Daneshvar, et al.,"Impact of optimal DG placement and sizing on power reliability and voltage profile of radial distribution networks," Majlesi Journal of Electrical Engineering, vol. 13, no. 2, pp. 91-102, 2019.

[32] K. Adetunji, I. Hofsajer, and L. Cheng, "Optimal DG allocation and sizing in power system networks using swarmbased algorithms," arXiv preprint arXiv:2002.08089, 2020.

[33] A. K. Arya, et al., "Assessment of Deployment of DGs and D-STATCOMs in Distribution Network using Gravitational Search Algorithm,"International Journal of Recent Technology and Engineering (IJRTE), vol. 8, no. 5, pp. 119-127, 2020.

[34] D. Kim, and I. Kim, "The Newton-Raphson method for optimization of distributed generation resources," 2019 IEEE Transportation Electrification Conference and Expo, Asia-Pacific (ITEC Asia-Pacific), Seogwipo-si, Korea (South), 2019, pp. 1-4.

[35] N. Rugthaicharoencheep, and S. Auchariyamet, "Technical and economic impacts of distributed generation on distribution system," World Academy of Science, Engineering and TechnologyInternational Journal of Electrical and Computer Engineering, vol. 6, no. 4, pp. 385-389, 2012.

[36] A. Elrayyah, Y. Sozer, and M.E. Elbuluk, "A novel load-flow analysis for stable and optimized microgrid operation," IEEE Transactions on Power Delivery, vol. 29, no. 4, pp. 1709-1717, 2014.

[37] A. M. Eltamaly, et al.,"Impact of distributed generation ( $\mathrm{dg}$ ) on the distribution system network," Annals of the Faculty of Engineering Hunedoara, vol. 17, no. 1,pp. 165-170, 2019.

[38] R. G. Srinivasa, and Y. P. Obulesh, "Voltage profile improvement of distribution system using distributed generating units," International Journal of Electrical and Computer Engineering, vol. 3, no. 3, pp. 337, 2013.

[39] I. Labed, and D. Labed, "Extreme learning machine-based alleviation for overloaded power system." IET Generation, Transmission \& Distribution, vol. 13, no. 22, pp. 5058-5070, 2019.

[40] R. D. Zimmerman, Ray Daniel, C. E. Murillo-Sánchez, and R. J. Thomas, "MATPOWER: Steady-state operations, planning, and analysis tools for power systems research and education," IEEE Transactions on Power Systems, vol. 26, no. 1, pp. 12-19, 2011.

[41] A. S. O. Ogunjuyigbe, T. R. Ayodele, and O. O. Akinola,"Impact of distributed generators on the power loss and voltage profile of sub-transmission network," Journal of Electrical Systems and Information Technology, vol. 3, no. 1 , pp. $94-107,2016$ 


\section{BIOGRAPHIES OF AUTHORS}

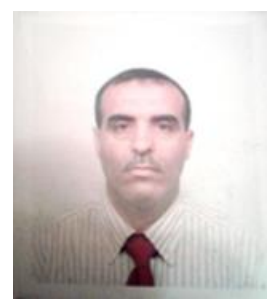

Tebbakh Noureddine: was born in Tadjenanet, Algeria in (1971), he received his B.S and M.S degrees in Electrical Engineering Power system from Setif 1 University (Algeria) in 1994 and 2017 respectively. He is currently a Ph.D. student at a laboratory of Electric Engineering, Department of Electrical Engineering Constantine. University of Constantine 1(Algeria).

His research activities are currently interesting on distributed generation impact on voltage profile and energy losses on the electrical power system.

E-mail: tebbakh.noureddine@yahoo.com

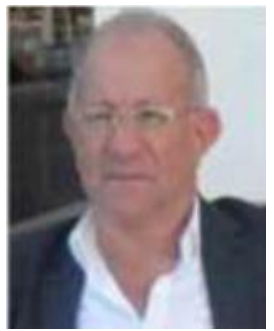

Labed Djamel: received his B.Sc. degree in Electrical Engineering from the University of Annaba, Algeria, in 1983, the M.Sc. degree in Electrical Research Network from the Ecole Polytechnique of Montreal, Canada, in 1986, and a Ph.D. degree in Electrical Engineering from Mentouri University of Constantine, Algeria.

In 1987, he joined Mentouri University Constantine, Algeria, has lecturer with the Department of Electrical Engineering, where he has been a Full Professor, and actually he is Director of Electrical Engineering Laboratory Constantine LGEC.

His research activities focus on: Impacts of Distributed Generation; Different techniques for optimizing the optimal power flow; Identification of the weakest buses to facilitate the search for optimal location of Var sources; Extreme learning machine based alleviation For overloaded power system; Stability of groups; Power flow method for DC networks integrated into AC; Analysis of various kinds of issue quality of electric power caused by renewable energy sources. E-mail: djamel_labed@yahoo.fr 